\title{
Preparation and characterization of nickel oxide nanoparticles and their application in glucose and methanol sensing
}

\author{
Mahsa Hasanzadeh ${ }^{\mathrm{a}, \mathrm{b}}$ and Reza Emamali Sabzi ${ }^{\mathrm{a}, \mathrm{b}^{*}}$
}

${ }^{a}$ Department of Chemistry, faculty of Science, Urmia University post code 57561-51818, Urmia, I.R. Iran ${ }^{b}$ Institute of Biotechnology, Urmia University, post code 57561-51818, Urmia, I.R. Iran

\begin{tabular}{|c|c|}
\hline CHRON I C LE & A B S T RAC T \\
\hline $\begin{array}{l}\text { Article history: } \\
\text { Received October 21, } 2014 \\
\text { Received in revised form } \\
\text { January 29, } 2015 \\
\text { Accepted } 8 \text { March } 2015 \\
\text { Available online } \\
8 \text { March } 2015 \\
\end{array}$ & $\begin{array}{l}\text { In this work, a low cost glucose and methanol nonenzymatic sensor was prepared using nickel } \\
\text { oxide (NiO) nanofilm electrodeposited on a bare Cu electrode. Electrochemical deposition was } \\
\text { assisted with cetyl trimethylammonium bromide (CTAB) as a template. Scanning electron } \\
\text { microscopy (SEM) was applied to observe the surface morphology of the modified electrode. } \\
\text { Cyclic voltammetry (CV) and amperometry techniques were used to study the electrocatalytic } \\
\text { behavior of NiO porous film in glucose and methanol detection. For glucose sensing, the }\end{array}$ \\
\hline $\begin{array}{l}\text { Keywords: } \\
\text { Electrocatalysis } \\
\text { Nickel oxide } \\
\text { Glucose sensor } \\
\text { Electrochemical sensor } \\
\text { Nonenzymatic sensor }\end{array}$ & $\begin{array}{l}\text { limit of detection (LOD) } 1.7 \mu \mathrm{M} \text { (signal/noise ratio }(\mathrm{S} / \mathrm{N})=3 \text { ). Moreover, high sensitivities of } \\
4.02 \mathrm{~mA} \mathrm{mM} \mathrm{m}^{-1} \mathrm{~cm}^{-2} \text { and } 0.38 \mathrm{~mA} \mathrm{mM} \mathrm{m}^{-1} \mathrm{~cm}^{-2} \text { respectively in glucose and methanol monitoring } \\
\text { suggested the modified electrode as an excellent sensor. The NiO-Cu modified electrode was } \\
\text { relatively insensitive to common biological interferers. This sensor possessed good poison } \\
\text { resistance towards chloride ions, and long term stability and significant selectivity towards } \\
\text { glucose and methanol. Finally the proposed sensor was successfully applied for determination } \\
\text { of glucose in human blood serum samples. }\end{array}$ \\
\hline
\end{tabular}

\section{Introduction}

Diabetes is a metabolic disorder, a major health problem all over the world and has affected more than 220 million people over the past few decades ${ }^{1,2}$. Electrochemical methods have potential application in the detection of D-(+)-glucose in blood samples ${ }^{3}$. Over the past decades, a number of studies have been conducted to reduce the disadvantages of enzymatic glucose sensors. The most common and serious problem was low stability due to the nature of the enzymes, which was hardly overcome. Although glucose oxidase (GOD) is quite stable compared with other enzymes, glucose sensors based on GOD are always vulnerable against thermal and chemical deformations during fabrication, storage or use. In addition, GOD quickly loses its activity in pH values below 2 and above 8 and temperatures above $40{ }^{\circ} \mathrm{C}$ can cause fatal damages ${ }^{4}$. To overcome the above obstacles, non-

\footnotetext{
* Corresponding author.

E-mail address: reza.emamalisabzi@gmail.com (M. Hasanzadeh)
} 
enzymatic glucose sensors have been developed and kept coming closer to practical applications ${ }^{5}$. Methanol is one of the most commonly used volatile organic solvents, especially in industries and laboratories. Long-term exposure to methanol vapor could result in medical conditions such as headaches, eyesight disturbance and death. Therefore, the precise monitoring of the methanol concentration in a given environment is crucial. Developing a sensor that can rapidly and reliably evaluate methanol concentration is necessary ${ }^{6}$. Recently considerable researches have been concentrated on the use of low-cost metal oxide materials such as $\mathrm{NiO}^{7-9}$, manganese oxide ${ }^{10}$ and zinc oxide $^{11}$. NiO has received a great attention because of its good electrochemical stability and electrocatalytic activity as well as low cost for a wide variety of applications ${ }^{12}$. In the present study, because of the large specific area and good electrocatalytic properties of $\mathrm{NiO}$, the NiO-nanoparticles modified $\mathrm{Cu}$ electrode was investigated as an electrocatalyst for glucose and methanol determination in an alkaline media.

\section{Results and Discussion}

\subsection{Fabrication and characterization of $\mathrm{NiO}$ modified electrode}

The Ni film was directly deposited on an ultrasonically cleaned bare Cu electrode using CTAB as template. It is well known that CTAB can form different shapes at different concentrations in aqueous solution ${ }^{13}$. Under a negative applied potential of $-1 \mathrm{~V}$ and in presence of CTAB as a soft template, $\mathrm{Ni}^{2+}$ ions, started to electrodeposit on the surface of the electrode in the form of Ni particles. The possible role of the CTAB is illustrated in Scheme 1. As shown in the scheme, Ni deposits had negative charge due to the adsorption of $\mathrm{SO}_{4}{ }^{2-}$ ions. Therefore, the cationic surfactant (CTAB) interacted with negatively charged deposits through electrostatic cohesion. After washing the electrode surface with double distilled (DD) water, CTAB was removed from the surface and a porous nanostructured Ni film was appeared. In comparison with other physical/chemical methods for the fabrication of sensor electrodes, such as sputtering, electro-spinning, chemical vapor deposition, solvothermal synthesis and thermal decomposition, this electrodeposition route does not require complicated equipment and operations ${ }^{14}$. In the next step, the resulting electrode was immersed in $0.3 \mathrm{M} \mathrm{NaOH}$ solution to fabricate nickel oxides and also determine glucose and methanol. Use of porous films with non-uniform pores would result in better efficiency compared to traditional porous films ${ }^{15}$. Examination with SEM displayed a non-uniformed porous structure with nanoscaled morphology of the NiO deposits as shown in Fig. 1. The peak current of modified electrode and the redox peak potentials were almost equal after fifty scan. Therefore, we concluded that $\mathrm{NiO}$ film had good stability. The electrochemical reactions of $\mathrm{Ni}^{2+} / \mathrm{Ni}^{3+}$ are as follows ${ }^{16}$ :

$$
\begin{gathered}
\mathrm{NiO}+\text { physisorbed water } \rightarrow \mathrm{NiO} \cdot \mathrm{H}_{2} \mathrm{O} \\
\mathrm{NiO} \cdot \mathrm{H}_{2} \mathrm{O} \text { (Strongly adsorbed on the surface layer) } \\
\mathrm{NiO}+\mathrm{OH} \rightarrow \mathrm{Ni}(\mathrm{OH})_{2}
\end{gathered}
$$

$\mathrm{Ni}(\mathrm{OH})_{2}$ is extremely sensitive to electron exposure, and therefore, a pair of redox peaks appear due to the following reaction ${ }^{16}$ :

$$
\mathrm{Ni}(\mathrm{OH})_{2}+\mathrm{OH} \quad \leftrightarrow \quad \mathrm{NiOOH}+\mathrm{H}_{2} \mathrm{O}+\mathrm{e}^{-}
$$

For efficacy control, cyclic voltammograms of the bare $\mathrm{Cu}$ electrode and $\mathrm{NiO}$ modified $\mathrm{Cu}$ electrode were compared as shown in Fig. 2. According to Fig. 2 anodic and cathodic peaks were attributed to redox pairs $\mathrm{Ni}^{2+} / \mathrm{Ni}^{3+}$ which was consistent with the results of the reference article ${ }^{12}$. The electrochemical behavior of the modified electrode was studied using CV technique. 


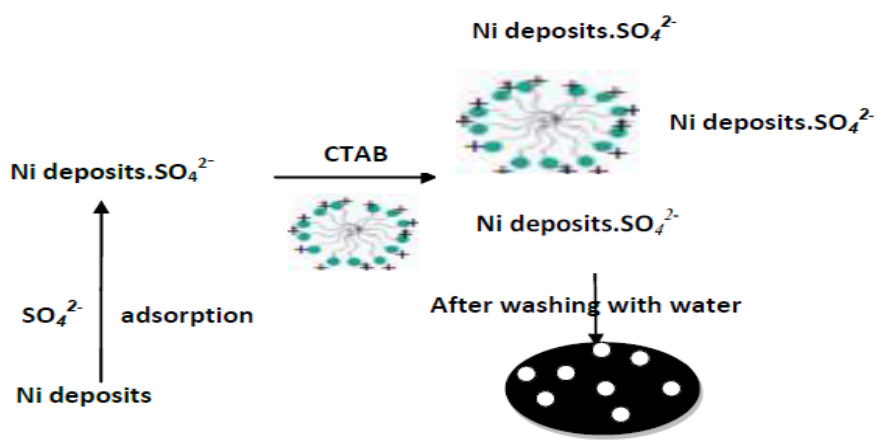

Scheme 1. Strategy for fabricating nanosized porous Ni film assisted with CTAB.

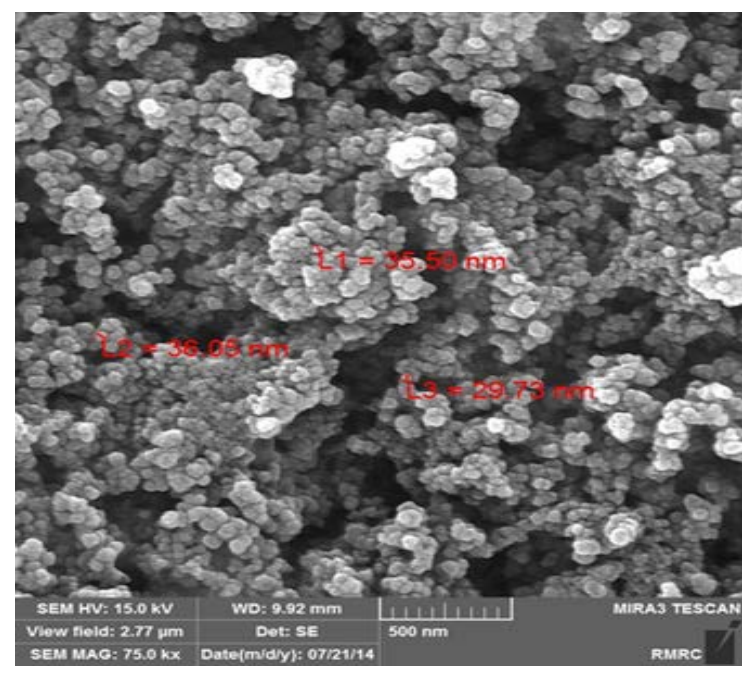

Fig. 1. SEM image of the NiO modified electrode

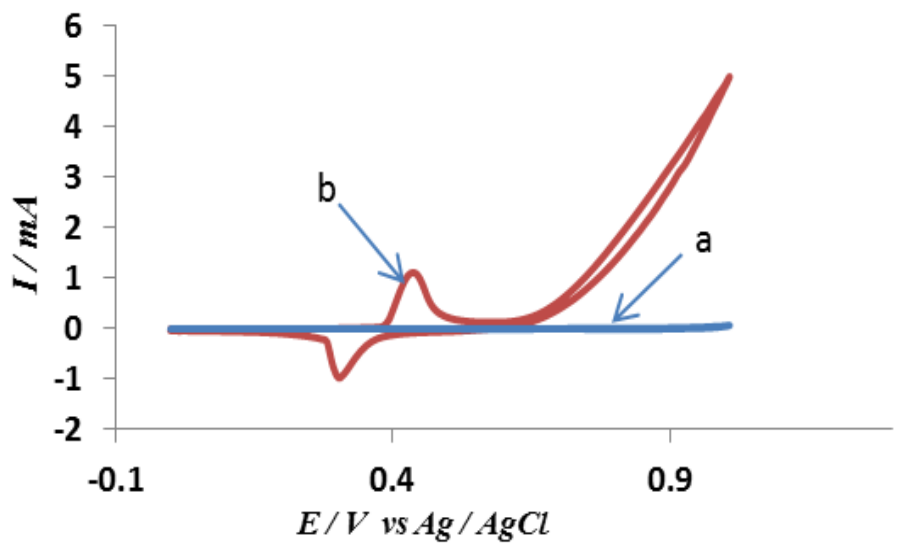

Fig. 2. Comparison of cyclic voltammograms in $0.3 \mathrm{M}$ $\mathrm{NaOH}$ solution: a) bare $\mathrm{Cu}$ electrode and b) $\mathrm{NiO}$ modified $\mathrm{Cu}$ electrode

\subsection{Electro-oxidation behavior of glucose and methanol on the surface of nanostructured NiO modified electrode}

In this work, $\mathrm{NiO}$ modified electrode was studied as an electrocatalyst in glucose and methanol sensing. Investigating electro-catalytic behavior of $\mathrm{NiO}$ towards glucose and methanol was accomplished with recording cyclic voltammograms at $0.05 \mathrm{~V} \cdot \mathrm{s}^{-1}$ in presence and absence of analysts. As shown in Fig. 3, in the presence of glucose an increase in anodic peak charge and reversely a light decrease in cathodic peak were observed which were indicative of an irreversible reaction on the electrode surface. Fig. 4 shows that increasing methanol concentration in the solution causes a linear increase in oxidation peak current. It should be mentioned that, in glucose and methanol determination, amperometry technique was applied rather than CV.

\subsection{Amperometric detection of glucose with $\mathrm{NiO}$ modified electrode}

All of the parameters which affected the experiments were optimized; i.e. $\mathrm{NiSO}_{4}, \mathrm{CTAB}$ and $\mathrm{NaOH}$ concentration, applied potential and electrodeposition time of $\mathrm{NiO}$ film on electrode surface. Applied potential for amperometric detection of glucose and methanol was also optimized and $+0.5 \mathrm{~V}$ was chosen as the best potential. Fig. 5 shows amperometric current response upon addition of different concentrations of glucose in $0.3 \mathrm{M} \mathrm{NaOH}$ electrolyte. According to Fig. 6 the electrode exhibited a linear relationship in the concentration range of $10 \mu \mathrm{M}$ to $2.14 \mathrm{mM}$ with a LOD of $0.0017 \pm\left(2 / 2 \times 10^{-4}\right)$ $\mathrm{mM}(\mathrm{S} / \mathrm{N}=3, \mathrm{n}=3$ and confidence limit $=95 \%)$ for glucose determination. The sensitivity of the sensor for glucose monitoring was calculated to be $4.02 \mathrm{~mA} \cdot \mathrm{mM}^{-1} \mathrm{~cm}^{-2}$ which is significant in comparison with values reported for graphene/NiO nanocomposites $\left(1.57 \mathrm{~mA} \cdot \mathrm{mM}^{-1} \cdot \mathrm{cm}^{-2}\right)^{12}$, Ni nanoparticles/SWNTs modified electrode $\left(1.44 \mathrm{~mA} \cdot \mathrm{mM}^{-1} \cdot \mathrm{cm}^{-2}\right)^{17}, \mathrm{Cu}_{\mathrm{x}} \mathrm{O}$ modified electrode (1.62 
$\left.\mathrm{mA} \cdot \mathrm{mM}^{-1} \cdot \mathrm{cm}^{-2}\right)^{18}$ and $\mathrm{Cu}_{2} \mathrm{O} / \mathrm{SMWNTs}$ modified electrode $\left(2.14 \mathrm{~mA} \mathrm{mM} \mathrm{mM}^{-1} \cdot \mathrm{cm}^{-2}\right)^{19}$. The performance of the prepared electrode in glucose detection was compared with those obtained from some other existing enzymeless glucose sensors. As shown in Table 1, the prepared sensor was the best among the compared sensors because of its excellent sensitivity, low LOD and wide linear range. Selectivity against interfering species is very important for a sensor. Amperometric current upon addition of glucose and common interfering species such as AA, UA and DA in biological samples is displayed in Fig. 6. For most of the nonenzymatic glucose sensors based on precious metals and alloys, the activity can be easily lost due to the poisoning of chloride ions ${ }^{20,21}$. Therefore, amperometric response of the modified electrode towards glucose was almost constant in $0.3 \mathrm{M} \mathrm{NaOH}$ electrolyte in the presence and absence of $0.45 \mathrm{M} \mathrm{NaCl}$ solution. Thus, the proposed sensor had significant poison-resistance ability towards high concentrations of chloride ions. Finally, the proposed nonenzymatic glucose sensor based on $\mathrm{NiO}-\mathrm{Cu}$ electrode was applied to detect glucose in human blood serum samples at potential $+0.5 \mathrm{~V}$ in $0.3 \mathrm{M} \mathrm{NaOH}$ using amperometric technique. Glucose concentration was found by drawing calibration curve. The response of the prepared electrode for glucose monitoring in real samples was confirmed well against the values obtained from a local hospital.

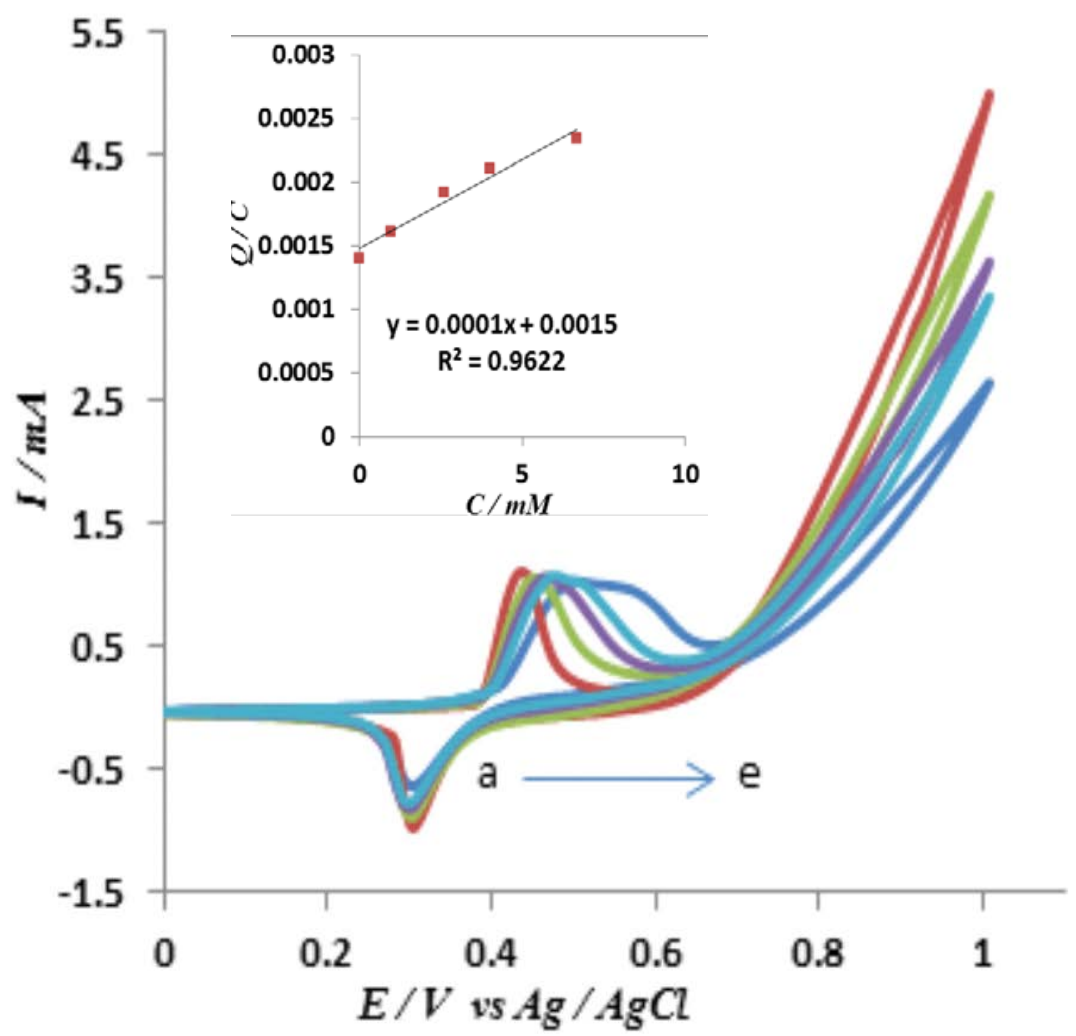

Fig. 3. Shows the cyclic voltammograms of modified electrode at $0.05 \mathrm{~V} \cdot \mathrm{s}^{-1}$ in $0.3 \mathrm{M} \mathrm{NaOH}$ electrolyte with glucose concentrations respectively: a) 0, b) 0.95 , c) 2.61 , d) 4 and e) $6.67 \mathrm{mM}$. The inset shows the plot of corresponding anodic peak charge versus glucose concentration 


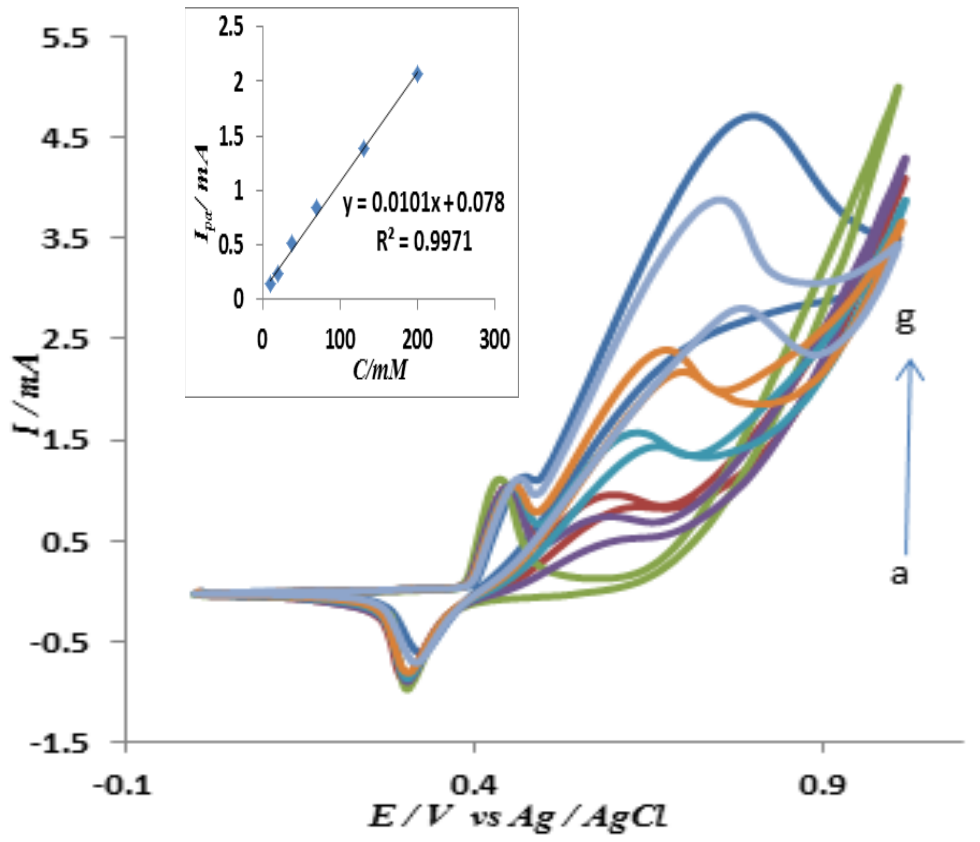

Fig. 4. Electro-oxidation behavior of modified electrode at $0.05 \mathrm{~V} \mathrm{~s}^{-1}$ in $0.3 \mathrm{M} \mathrm{NaOH}$ supporting electrolyte respectively: a) 0, b) 0.01 , c) 0.02 , d) 0.04 , e) 0.07 , f) 0.13 and g) $0.2 \mathrm{mM}$ methanol. Inserted plots are relevant to cyclic voltammograms of Fig. 4

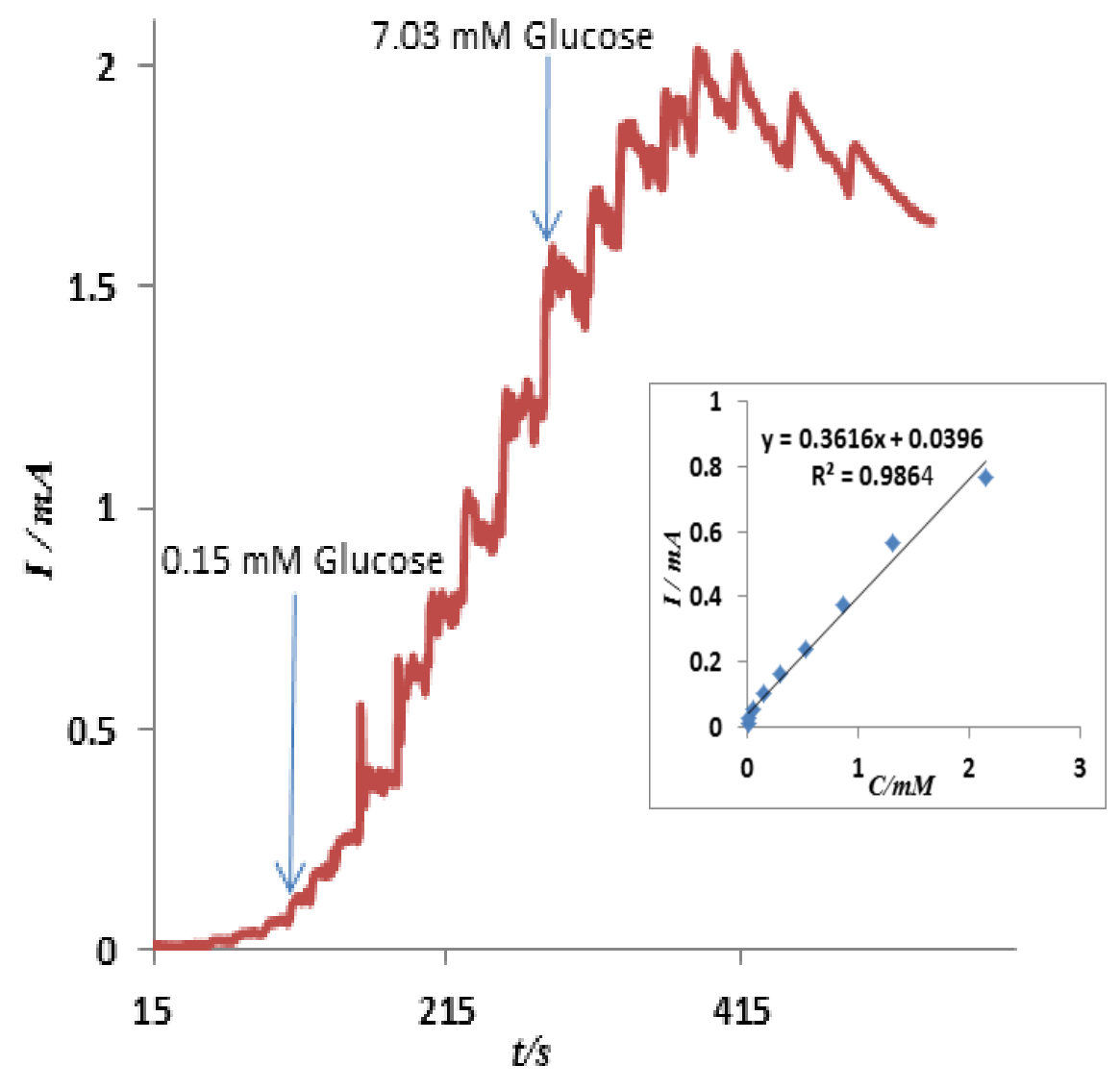

Fig. 5. Hydrodynamic amperogram upon addition of different concentrations of glucose in $0.3 \mathrm{M} \mathrm{NaOH}$ supporting electrolyte. The inset plot shows the corresponding calibration curve 


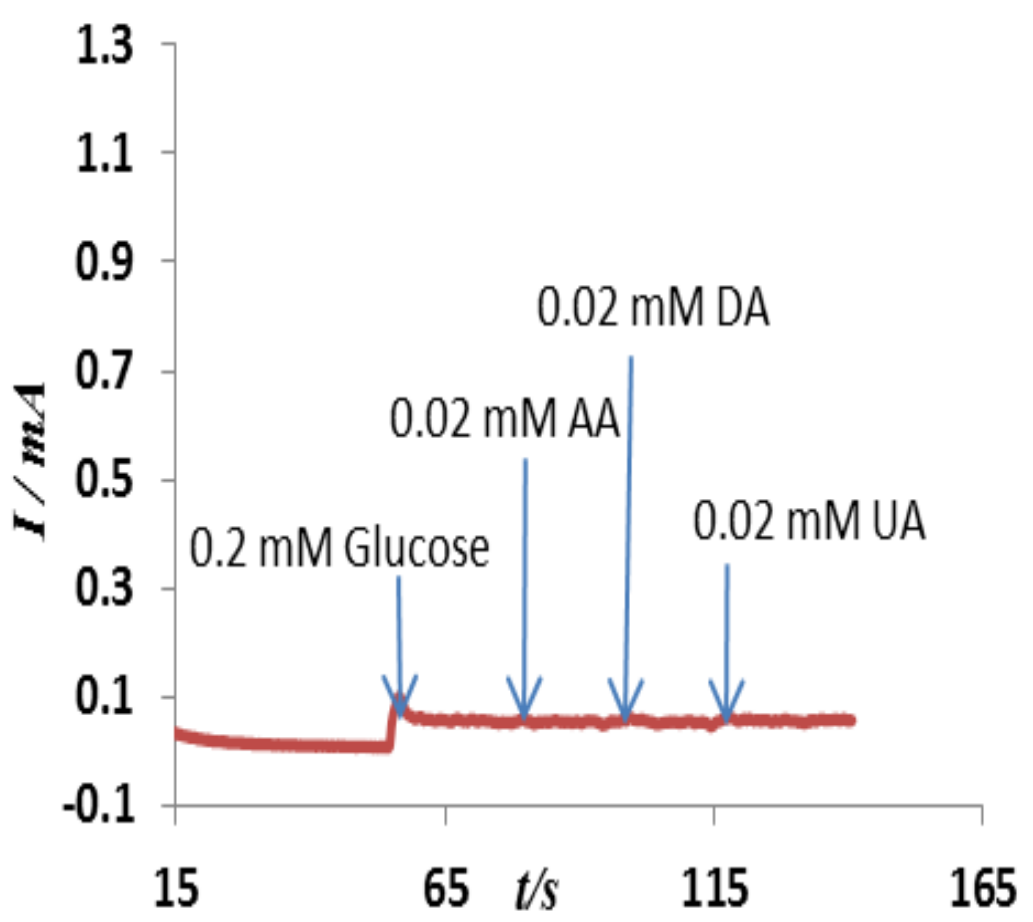

Fig. 6. Amperometric current upon additıon ot glucose and common intertering species

\subsection{Amperometric detection of methanol with $\mathrm{NiO}$ modified electrode}

The prepared sensor was also applied in methanol detection. Under optimized conditions applied potential of $+0.5 \mathrm{~V}$
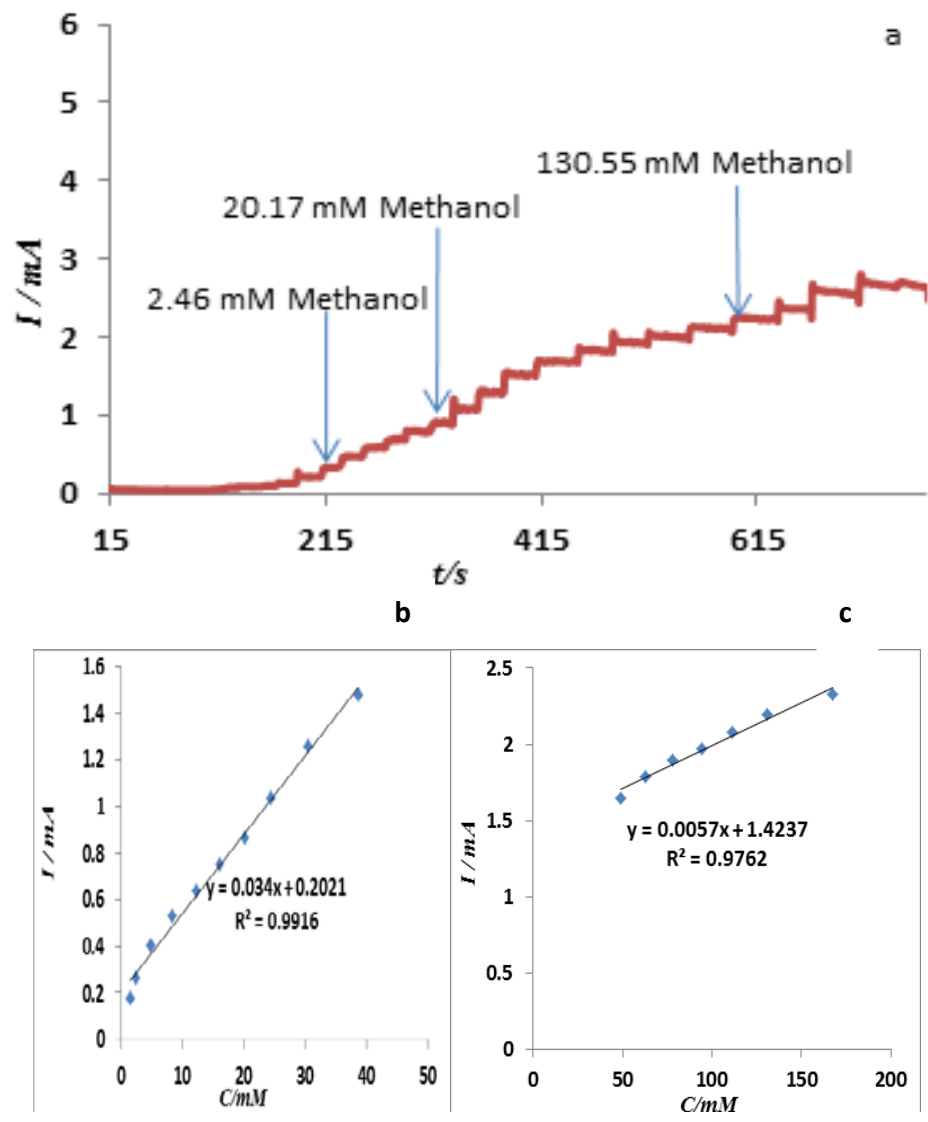

Fig. 7a. Hydrodynamic amperogram of successive additions of methanol to $0.3 \mathrm{M} \mathrm{NaOH}$ electrolyte. $\mathrm{b}$ and c exhibit the amperometric current response versus methanol concentration (calibration curves) 
Fig. 7a represents the successive addition of methanol to $0.3 \mathrm{M} \mathrm{NaOH}$ electrolyte. Figs. $7 \mathrm{~b}$ and c exhibit corresponding calibration curves. This methanol sensor displayed two linear ranges from 1.50 to $38.57 \mathrm{mM}$ and 49.28 to $167.06 \mathrm{mM}$ with LOD of $0 / 82 \pm\left(1.1 \cdot 10^{-2}\right) \mathrm{mM}(\mathrm{S} / \mathrm{N}=3, \mathrm{n}=3$ and confidence level $=95 \%$ ). The regression equation for the first linear range was $\mathrm{I}=0.034 \mathrm{C}+0.2021$ with correlation coefficient of 0.9916 . The sensitivity of the sensor for methanol detection was $0.38 \mathrm{~mA} \mathrm{mM} \mathrm{mm}^{-1}$ which is very high in comparison with sensitivities of other methanol sensors such as: CEF$\mathrm{Ni}(\mathrm{II}) /$ Chitosan/GC $\left(0.002 \mathrm{~mA} \cdot \mathrm{mM}^{-1} \cdot \mathrm{cm}^{-2}\right)^{22}$, Methanol dehydrogenase $\left(0.02 \mathrm{~mA} \cdot \mathrm{mM}^{-1} \cdot \mathrm{cm}^{-2}\right)^{23}$, etc. Comparison of the present $\mathrm{NiO}-\mathrm{Cu}$ modified electrode with other existing methanol sensors is presented in Table 2; according to this table the proposed sensor is an excellent methanol sensor due to its high sensitivity and wide linear ranges. Thus, the facile fabrication and determination procedures based on electrochemically prepared $\mathrm{NiO}-\mathrm{Cu}$ modified electrode provides enough potential for the sensor to be applicable in monitoring methanol concentration in the alcoholic beverages and other samples.

Table 1. Comparison of the present $\mathrm{NiO}-\mathrm{Cu}$ modified electrode with other existing nonenzymatic glucose sensors

\begin{tabular}{cccc}
\hline working electrode & $\begin{array}{c}\text { Sensitivity } \\
\left(\mathrm{mA} \cdot \mathbf{m M}^{-1} \cdot \mathbf{c m}^{-2}\right)\end{array}$ & LOD $(\mu \mathrm{M})$ & Reference \\
\hline NiO-Cu & 4.02 & 1.7 & This work \\
NiONPs/GO & 1.09 & 1 & {$[24]$} \\
CoOOH nanosheets & 0.34 & 30.9 & {$[25]$} \\
CS-RGO-NiNPs & 3.18 & 4.4 & {$[26]$} \\
GP/NiO & 1.57 & 1 & {$[12]$} \\
\hline
\end{tabular}

Table 2. Comparison of some parameters for methanol sensors

\begin{tabular}{cccc}
\hline Working electrode & $\begin{array}{c}\text { Sensitivity } \\
\left(\mathrm{mA} \cdot \mathrm{mM}^{-1} \cdot \mathrm{cm}^{-2}\right)\end{array}$ & Linear range (mM) & Reference \\
\hline NiO-Cu & 0.38 & $1.50-38.57$ and 49.28-167.06 & This work \\
GP/NiO & 0.002 & $0.2-24$ & {$[12]$} \\
Pt/CNTs & 0.006 & $25-100$ & {$[27]$} \\
Twin Nafion membrane & 0.06 & $500-2000$ & {$[28]$} \\
\hline
\end{tabular}

\subsection{Stability and reproducibility of the sensor}

Stability and reproducibility are two important factors for evaluating efficiency of sensors. In this research, stability of $\mathrm{NiO}$ modified electrode was evaluated over a one-month period. The sensor was stored at $4{ }^{0} \mathrm{C}$ in refrigerator and was tested each day for ten consecutive days and every five days over the next 20 days. The response of the developed sensor after one month was decreased only $5.6 \%$ and $6.3 \%$ respectively towards glucose and methanol detection according to amperometric current response. Moreover, we examined the reproducibility of the sensor by detecting amperometric current responses towards $0.08 \mathrm{mM}$ glucose and $12.83 \mathrm{mM}$ methanol in $0.3 \mathrm{M} \mathrm{NaOH}$ solution. The results of 
7 repeated tests for each analyte indicated that the proposed sensor had acceptable reproducibility with a relative standard deviation (RSD) of $7.4 \%$ and $7.3 \%$ for glucose and methanol sensing respectively.

\section{Conclusions}

In this research, a new enzymeless sensor for methanol and glucose was fabricated based on $\mathrm{NiO}$ nanoparticles electrodeposited on a Cu electrode with CTAB as a soft template. The unique porous and nanostructured surface of the modified electrode enhanced the electro-catalytic behavior of $\mathrm{NiO}$ in methanol and glucose oxidation. As a result, the proposed sensor could be applied as a sensor owing to its high sensitivity in glucose $\left(4.02 \mathrm{~mA} \cdot \mathrm{mM}^{-1} \cdot \mathrm{cm}^{-2}\right)$ and methanol $\left(0.38 \mathrm{~mA} \cdot \mathrm{mM}^{-1} \cdot \mathrm{cm}^{-2}\right)$ detection, low LOD in glucose monitoring $(1.7 \mu \mathrm{M})$ and two wide linear ranges (1.50-38.57 and 49.28-167.06 $\mathrm{mM}$ ) in methanol sensing, low cost, facile preparation method, high stability, and satisfying precision and accuracy. On the other hand, the proposed sensor was successfully used in glucose monitoring in real samples.

\section{Experimental}

\subsection{Materials and apparatus}

D-(+)-Glucose monohydrate, methanol (99.99\%), $\mathrm{NiSO}_{4} .6 \mathrm{H}_{2} \mathrm{O}, \mathrm{NaOH}, \mathrm{CTAB}, \mathrm{AA}, \mathrm{UA}$, DA and $\mathrm{NaCl}$ were all purchased from Merck. Blood serum sample was obtained from a local hospital. The 0.3 mol L $\mathrm{L}^{-1} \mathrm{NaOH}$ solution was used as supporting electrolyte for the electrochemical analysis. Double distilled (DD) water was used in all experiments. Electrochemical measurements were carried out on a $\mu$ Autolab type III (made in the Netherlands). The surface of the electrode was cleaned with an ultrasonicator (parasonic mini, Pars Nahad Co., Iran). SEM images were obtained using a MIRA3 TESCAN SEM (Razi metallurgical research center (RMRC), Iran). All experiments were repeated at least three times.

\subsection{Modified electrode fabrication}

First, $\mathrm{Cu}$ electrode was polished by a 400 then 2000 grit emery paper, then the electrode surface was cleaned with ultrasonication in DD water for a few minutes and then the electrode was washed with DD water to remove surface impurities. In this study, porous $\mathrm{Ni}$ foam was generated on the bare $\mathrm{Cu}$ electrode using CTAB as a soft template in electrodeposition process. Under optimized conditions, the cleaned electrode was immersed into a mixture of $0.6 \mathrm{M} \mathrm{NiSO}_{4}$ and $0.02 \mathrm{M} \mathrm{CTAB}$, followed by an electrodeposition process with a constant potential of $-1 \mathrm{~V}$ for $900 \mathrm{~s}$, during which nickel nanoparticles were deposited on the surface of the electrode; afterwards, the Ni-Cu foam was rinsed with DD water and dried carefully in air for the next electrochemical experiment. In the second stage, the resulting electrode was immersed in $0.3 \mathrm{M} \mathrm{NaOH}$ solution and $\mathrm{CV}$ technique was performed at potential range 0.2-1 V until stable cyclic voltammograms were obtained. By doing so, Ni deposits were converted to $\mathrm{NiO}$ on the surface of the electrode. This modified electrode was used to evaluate glucose and methanol concentrations.

\subsection{Electrochemical measurements}

All of the tests were performed with a conventional three electrode system consisting of $\mathrm{Cu}$ electrode with $3 \mathrm{~mm}$ in diameter as a working electrode, and a Pt wire as a counter electrode; in this study all potentials were measured against $\mathrm{Ag} / \mathrm{AgCl}$ electrode ( $\mathrm{KCl}$ saturated). All of the experiments were performed in stationary state except amperometric measurements which were carried out by injecting analytes into $0.3 \mathrm{M} \mathrm{NaOH}$ solution while stirring constantly (150 rpm). All the experiments were accomplished at room temperature. 


\section{References}

1. Wang, Y.L., Xu, Y.H., Luo, L.Q., Ding, Y.P., Liu, X.J. and Huang, A.Q. (2010) A novel sensitive nonenzymatic glucose sensor based on perovskite LaNi0.5Ti0.5O3-modified carbon paste electrode. Sens. Actuators , B: Chem. 151, 65-70.

2. Reitz, E., Jia, W.Z., Gentile, M., Wang, Y. and Lei, Y. (2008) CuO nanospheres based nonenzymatic glucose sensor. Electroanalysis 20, 2482-2486.

3. Reach, G. and Wilson, G.S. (1992) Can continuous glucose monitoring be used for the treatment of diabetes. Anal. Chem. 64, 381A-386A.

4. Wilson, R. and Turner, A.P.F. (1992) Glucoseoxidase an ideal enzyme. Biosens. Bioelectron. 7, 165185.

5. Park, S., Boo, H. and Chung, T.D. (2006) Electrochemical non-enzymatic glucose sensors. Anal. Chim. Acta, 556, 46-57.

6. Wrobel, K., Rodríguez, D.M., Aguilar, F.J.A. and Wrobel, K. (2005) Determination of methanol in o,o-dimethyldithiophosphoric acid (DMDTPA) of technical grade by UV/vis spectrophotometry and by HPLC. Talanta 66, 125-129.

7. Berchmans, S., Gomathi, H. and Prabhakara, Rao, G. (1995) Electrooxidation of alcohols and sugars catalysed on a nickel oxide modified glassy carbon electrode. J. Electroanal. Chem. 394, 267-270.

8. You, T., Niwa, O., Chen, Z., Hayashi, K., Tomita, M. and Hirono, S. (2003) An amperometric detector formed of highly dispersed Ni nanoparticles embedded in a graphite-like carbon film electrode for sugar determination. Anal. Chem. 75, 5191-5196.

9. Ding, Y., Wang, Y., Su, L., Zhang, H. and Lei, Y. (2010) Preparation and characterization of NiOAg nanofibers, $\mathrm{NiO}$ nanofibers, and porous Ag: towards the development of a highly sensitive and selective non-enzymatic glucose sensor. J. Mater. Chem. 20, 9918-9926.

10. Chen, J., Zhang, W.D. and Ye, J.S. (2008) Nonenzymatic electrochemical glucose sensor based on $\mathrm{MnO}_{2} / \mathrm{MWNTs}$ nanocomposite. Electrochem. Commun. 10, 1268-1271.

11. Zang, J., Chang, M.L., Cui, X., Wang, J., Sun, X., Dong, H. and Sun, C.Q. (2007) Tailoring zinc oxide nanowires for high performance amperometric glucose sensor. Electroanalysis 19, 10081014.

12. Li, S.J., Xia, N., Lv, X.L., Zhao, M.M., Yuan, B.Q. and Pang, H. (2014) A facile one-step electrochemical synthesis of graphene/NiO nanocomposites as efficient electrocatalyst for glucose and methano. Sens. Actuators, B: Chem. 190, 809- 817.

13. Li, L. (2004) Surfactant and nanotechnology. Chemical industry publishing, Beijing, 2004, pp. 8388.

14. Niu, X., Li, Y., Tang, J., Hu, Y., Zhao, H. and Lan, M. (2014) Electrochemical sensing interfaces with tunable porosity for nonenzymatic glucose detection: A Cu foam case. Biosens. Bioelectro. 51, 22-28.

15. Shin, H.C. and Liu, M. (2004) Copper foam structures with highly porous nanostructured walls', Chem. Mater. 16, 5460-5464.

16. Prathap, M.U.A., Kaur, B. and Srivastava, R. (2012) Direct synthesis of metal oxide incorporated mesoporous SBA-15, and their applications in non-enzymatic sensing of glucose. J. Colloid Interface Sci., 381, 143-151.

17. Nie, H., Yao, Z., Zhou, X., Yang, Z. and Huang, S. (2011) Nonenzymatic electrochemical detection of glucose using well-distributed nickel nanoparticles on straight multi-walled carbon nanotubes. Biosens. Bioelectron. 30, 28-34.

18. Li, C., Su, Y., Zhang, S., Lv, X., Xia, H. and Wang, Y. (2010) An improved sensitivity nonenzymatic glucose biosensor based on a $\mathrm{Cu}_{\mathrm{x}} \mathrm{O}$ modified electrode. Biosens. Bioelectron. 26, 903-907.

19. Zhou, X., Nie, H., Yao, Z., Dong, Y., Yang, Z. and Huang, S. (2012) Facile synthesis of nanospindle-like $\mathrm{Cu}_{2} \mathrm{O} /$ straight multi-walled carbon nanotube hybrid nanostructures and their application in enzyme-free glucose sensing. Sens. Actuators B: Chem. 168, 1-7. 
20. Park, S., Chung, T.D. and Kim, H.C. (2003) Nonenzymatic glucose detection using mesoporous platinum. Anal. Chem. 75, 3046-3049.

21. Ye, J.S., Wen, Y., Zhang, W.D., Gan, L.M., Xu, G.Q. and Sheu, F.S. (2004) Nonenzymatic glucose detection using multi-walled carbon nanotube electrodes. Electrochem. Commun. 6, 66-70.

22. Liu, Y., Luo, S.L., Wei, W.Z., Liu, X.Y. and Zeng, X.D. (2009) Methanol sensor based on the combined electrocatalytic oxidative effect of chitosan-immobilized nickel(II) and the antibiotic cefixime on the oxidation of methanol in alkaline medium. Microchim. Acta 164, 351-355.

23. Liu, Q.F. and Kirchhoff, J.R. (2007) Amperometric detection of methanol with a methanol dehydrogenase modified electrode sensor. J. Electroanal. Chem. 601, 125-131.

24. Salimia, A., Noorbakhash, A., Sharifi, E. and Semnani, A. (2008) Highly sensitive sensor for picomolar detection of insulin at physiological $\mathrm{pH}$, using GC electrode modified with guanine and electrodeposited nickel oxide nanoparticles. Biosens. Bioelectron. 24, 792-798.

25. Lee, K.K., Loh, P.Y., Sow, C.H. and Chin, W.S. (2012) CoOOH nanosheets on cobalt substrate as a non-enzymatic glucose sensor. Electrochem. Commun. 20, 128-132.

26. Yang, J., Yu, J. H., Strickler, J.R., Chang, W. J. and Gunasekaran, S. (2013) Nickel nanoparticlechitosan-reducedgrapheneoxide-modified screen-printed electrodes for enzyme-free glucose sensing in portable microfluidic devices. Biosens. Bioelectron. 47, 530-538.

27. Kim, D.W., Lee, J.S., Lee, G.S., Overzet, L., Kozlov, M., Aliev, A.E., Park, Y.W. and Yang, D.J. (2006) Carbon nanotubes based methanol sensor for fuel cells application. J. Nanosci. Nanotechnol. 6, 3608-3613.

28. Selvaraj, V. and Alagar, M. (2007) Pt and Pt-Ru nanoparticles decorated polypyrrole/multiwalled carbon nanotubes and their catalytic activity towards methanol oxidation. Electrochem. Commun. 9, $1145-1153$. 